\title{
Variation in the reproductive development of perennial ryegrass (Lolium perenne L.) cultivars
}

\author{
C.M. WIMS ${ }^{1}$, J.M. LEE ${ }^{1}$, L. ROSSI ${ }^{2}$ and D.F. CHAPMAN ${ }^{2}$ \\ ${ }^{1}$ DairyNZ, Private Bag 3221, Hamilton 3240, New Zealand \\ ${ }^{2}$ DairyNZ, PO Box 160, Lincoln University, Canterbury 7647, New Zealand \\ cathal.wims@dairynz.co.nz
}

\begin{abstract}
Plant breeding has manipulated the flowering behaviour of perennial ryegrass (Lolium perenne L.) by developing later-heading cultivars. However, the impacts of breeding on the intensity and temporal distribution of flowering are not known. This study compared the reproductive development of 23 perennial ryegrass cultivar/endophyte combinations. In the Waikato and Canterbury, two replicate plots were closed from grazing and tillers were collected every two weeks over a 10 -week period during late spring and early summer. Plant development stage was determined for each tiller using a quantitative scale, which was then used to calculate the mean stage count of each cultivar. The rate and timing of reproductive development differed among cultivars. Mid-maturing cultivars matured earlier at both sites compared with late- and very late-maturing cultivars. While the intensity of flowering was similar between maturity groups, the temporal distribution of flowering varied: the late- and very late-maturing cultivars had lower proportions of reproductive tillers early in the season.
\end{abstract}

Keywords: Lolium perenne L., reproductive development, flowering behaviour

\section{Introduction}

The nutritive value (NV) and growth pattern of perennial ryegrass (Lolium perenne L.) in spring and summer are influenced by its flowering behaviour. Nutritive value declines in spring as plants move from vegetative to reproductive growth, in part due to changes in plant morphology as the stem:green leaf ratio increases (Waghorn et al. 2007). Controlling reproductive development in late spring and early summer, and thereby minimising the decline in pasture NV during this period, is an important pasture management objective of grazing systems aiming to optimise animal performance. To improve pasture NV during late-spring and early-summer, plant breeders have manipulated the flowering behaviour of perennial ryegrass by selecting for later-heading cultivars that maintain their leafiness for longer and retain better NV in spring (Lee et al. 2012).
Perennial ryegrass cultivars with a range of mean heading dates from -17 to +25 days (with day 0 typically 22 October in Canterbury) are now available in New Zealand. The heading date of perennial ryegrass is defined as the time when $50 \%$ of tillers show ear emergence (Lee et al. 2012). However, the impacts of plant breeding on the intensity and temporal distribution of flowering are largely unknown. Bahmani et al. (2002) reported that under grazing the cultivar 'Ellett' had a higher proportion of reproductive tillers compared with 'Ruanui' due to a higher conversion rate of vegetative to reproductive tillers (Fiorelli et al. 2001) despite having similar heading dates. However, there is little systematic information available to quantify the flowering dynamics of perennial ryegrass cultivars in grazed pastures. The objective of this study was to compare the reproductive development of perennial ryegrass cultivar/endophyte combinations spanning four decades of plant breeding.

\section{Methods}

The reproductive development of 23 perennial ryegrass cultivar/endophyte combinations was compared during late spring and early summer 2013 in a field experiment at two sites: DairyNZ Scott Farm, Hamilton (Waikato) and Lincoln University Research Dairy Farm, Lincoln (Canterbury). The experiment was sown in a rowcolumn design of four replicates on 26 April 2013 in the Waikato and on 4 April 2013 in Canterbury. All plots were grazed by dairy cows, on three occasions (from 23 June to 2 October) in the Waikato and on two occasions (28 August and 25 September) in Canterbury. Cultivars included mid-, late- and very late-maturing diploids and late- and very late-maturing tetraploids spanning four decades of plant breeding in New Zealand, from 'Nui' released in the 1970s to modern day material. Based on their expected heading date, cultivars were classified into one of three maturity groups (after Lee et al. 2012): mid-maturing (day 0 to +7 ), late-maturing (day +8 to +21 ) and very late-maturing (day $\geq+22$; Table 1 ). Two replicate plots of each cultivar were closed from grazing and approximately 120 tillers were collected fortnightly over a 10 -week period commencing on 10 October and 21 October for the Canterbury and Waikato sites, 
respectively. At each sampling, plant development stage was determined on a sub-sample of 30 randomly selected tillers per replicate. Plant development was scored according to the Moore et al. (1991) index for the elongation-stem elongation stages $\left(\mathrm{E} 0-\mathrm{E}_{\mathrm{n}}\right)$, and the reproductive-floral development (R0-R4) stages. The mean stage count (MSC) was calculated according to Equation 1 in Moore et al. (1991), and an adjusted MSC was derived as follows:

$$
\text { Adjusted MSC }=(\text { MSC- } 2) \times 100
$$

Tillers in each secondary growth stage $\left(\mathrm{E} 0-\mathrm{E}_{\mathrm{n}}, \mathrm{R} 0\right.$, R1, R2, R3 and R4) were bulked, dried and weighed so that the development stage of each cultivar could be compared on a dry weight basis, as well as a numerical basis. Daily minimum and maximum temperatures were used to calculate cumulative growing degree days
(GDD), above a base temperature of $5^{\circ} \mathrm{C}$, from 1 July (Table 2). Data were analysed using repeated measures analysis (Proc Mixed, SAS 9.3) with site, maturity group, sampling event, and their interactions included as fixed effects.

\section{Results}

At the commencement of the study, each maturity group was at a similar stage of development. The overall adjusted MSC was similar for both sites (Waikato 4.7; Canterbury 2.1; Figure 1) and virtually no reproductive tillers were present at either site (Figure 2). Thereafter, the mid-maturing cultivars matured earlier compared with the late- and very late-maturing cultivars $(\mathrm{P}<0.001$; Figures 1 and 2$)$ and maintained a higher adjusted MSC at both sites $(\mathrm{P}<0.001)$ until

Table 1 Cultivars and their associated endophyte included in the trial, grouped by heading date. Expected heading date (after Lee et al. 2012; days relative to 0 , where $0=22$ October) and ploidy ( $D=$ diploid, $T=$ tetraploid) are shown in brackets.

\begin{tabular}{ccc}
\hline Mid season & $\begin{array}{c}\text { Heading date } \\
\text { Late season }\end{array}$ & Very late season \\
\hline Nui SE $($ O, D) & Prospect AR37 $(+12, \mathrm{D})$ & Base AR37 $(+22, \mathrm{~T})$ \\
Bronsyn SE and AR1 (0, D) & Alto AR1 and AR37 $(+14, \mathrm{D})$ & Matrix SE $(+23, \mathrm{D})$ \\
Commando SE, AR1 and AR37 (+1, D) & Aberdart AR1 $(+15, \mathrm{D})$ & Quartet II Endo5 $(+25, \mathrm{~T})$ \\
Arrow AR1 $(+7, \mathrm{D})$ & Trojan NEA2 $(+16, \mathrm{D})$ & Bealey NEA2 $(+25, \mathrm{~T})$ \\
& Banquet II Endo5 $(+18, \mathrm{~T})$ & \\
& Abermagic AR1 $(+19, \mathrm{D})$ & \\
& One50 SE, AR1 and AR37 $(+20, \mathrm{D})$ & \\
\hline
\end{tabular}

Table 2 Sampling dates and cumulative growing degree days (GDD) from 1 July for the Waikato and Canterbury site

\begin{tabular}{ccc}
\hline \multicolumn{3}{c}{ Waikato } \\
\hline Sampling Event & Date & Cumulative GDD \\
1 & 21 October & 751 \\
2 & 4 November & 871 \\
3 & 18 November & 1021 \\
4 & 2 December & 1206 \\
5 & 16 December & 1385 \\
\hline & Canterbury & \\
\hline \multirow{2}{*}{ Sampling Event } & Date & Cumulative GDD \\
1 & 10 October & 440 \\
3 & 25 October & 560 \\
4 & 8 November & 661 \\
5 & 22 November & 799 \\
& 9 December & 984 \\
\hline
\end{tabular}

the completion of the study (Figure 1). A significant $(\mathrm{P}<0.001)$ maturity group by sampling date interaction was observed at both sites as the rate of reproductive development (defined as the change in adjusted MSC between successive samplings) differed between the maturity groups. Initially, the rate of reproductive development was greater for the mid-maturing cultivars at both sites. During the final measurement period the rate of reproductive development was greater for the late- and very late-maturing cultivars in the Waikato, while the rate of reproductive development was similar between maturity groups in Canterbury (Figure 1).

At the completion of the study, the proportion of tillers that had entered reproductive development was greater $(\mathrm{P}<0.01)$ for the mid-maturing cultivars $(0.76$ in Waikato and 0.70 in Canterbury) compared with the late- and very late-maturing cultivars (mean 0.64 in Waikato and 0.56 in Canterbury; Figure 2a). In the Waikato, the contribution of reproductive tillers to the total sample dry weight was similar between maturity groups (Figure $2 b$ ) while in Canterbury the contribution 


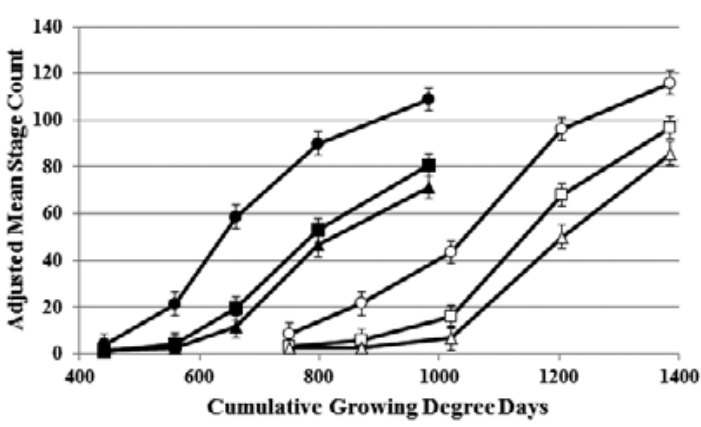

Figure 1 The adjusted mean stage count $( \pm S E D)$ of the total tiller sample over five successive sampling events during late spring and early summer in Canterbury (solid symbols) and Waikato (open symbols). Circles = mid-season heading cultivars; squares = late-season heading cultivars, triangles = very late-season heading cultivars. The maximum possible value for adjusted mean stage count is 200.

of mid-, late- and very late-maturing cultivars was significantly different $(\mathrm{P}<0.05$; Figure $2 \mathrm{~b})$, reflecting the trend in the proportion of tillers that had become reproductive (Figure 2a).

\section{Discussion}

For the purposes of this study, swards grew undefoliated for about 10 weeks to allow full expression of flowering behaviour. As a result, a higher proportion of tillers entered the later stages of reproductive development than would be expected under normal grazing management, where many stems are removed during the elongation stages (Korte 1986). The pattern of flowering relative to accumulated GDD since 1 July was very similar at both sites, even though the Waikato site accumulated 311 more GDD than the Canterbury site at the commencement of the study, and accumulated 90 GDD more than the Canterbury site during the measurement period. The expected differences in the timing of flowering between the mid-, late- and very late-maturing groups were observed at both sites, with the mid-maturing cultivars consistently showing higher adjusted MSC (Figure 1) and a higher proportion of tillers entering reproductive development (Figure 2a) compared with the late- and very late-maturing cultivars. In the mid-maturing category, a maximum of $70 \%$ of total tillers in Canterbury and $76 \%$ of total tillers in Waikato had entered reproductive development by the time of the fourth (Canterbury) or fifth (Waikato) sampling. This corresponds to a rate of between $0.17 \%$ (Waikato) and $0.20 \%$ (Canterbury) of tillers entering reproductive development per GDD. For the midmaturing cultivars, it appears that about $25-30 \%$ of tillers were not vernalised, most likely representing tillers produced in early spring (Korte 1986; L'Huillier
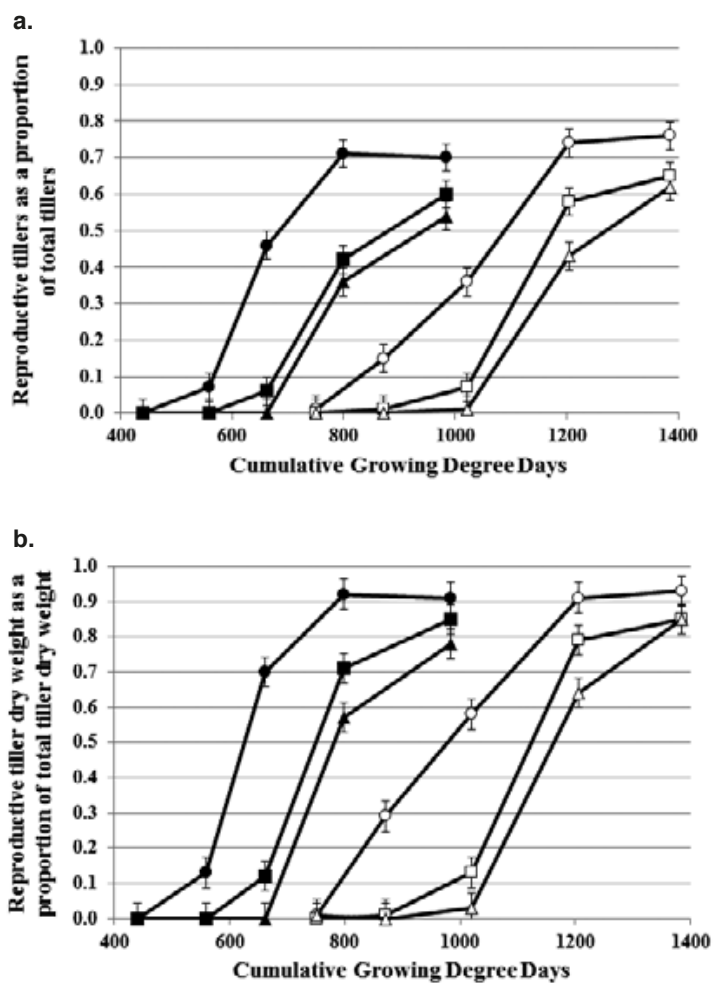

Figure 2 The contribution of reproductive tillers to the total tiller sample expressed as a) proportion of total tiller numbers, and b) proportion of total tiller dry weight, over five successive sampling events during late spring and early summer in Canterbury (solid symbols) and Waikato (open symbols). Circles = mid-season heading cultivars; squares = late-season heading cultivars, triangles = very late-season heading cultivars. Bars are \pm SED.

1987) which escaped the colder temperatures and short days required for vernalisation (Cooper \& Calder 1964). The proportion of tillers entering reproductive development was still increasing in the late- and very late-maturing cultivars at the end of the study, but the rate of reproductive tiller development appeared to start levelling off between the fourth and fifth samplings, indicating that the proportion of unvernalised tillers present in swards of these cultivars may have been similar to that in the mid-maturing cultivars. Future comparisons of flowering dynamics in perennial ryegrass cultivars need to continue for a longer period than was the case in this study to capture the full profile of reproductive tiller development, and allow for possible differences in aftermath heading (Forde et al. 1988).

Trends in the proportion of tillers entering reproductive development (Figure 2a) were largely mirrored by trends in the contribution of reproductive tillers to total tiller sample dry weight (Figure 2b), indicating that 
the intensity of reproductive development (defined as the mass of reproductive tillers as a proportion of total tillers) did not differ among maturity groups. However, no firm conclusions can be drawn because reproductive development in the late- and very late-maturing cultivars was incomplete at the end of the measurement period. Despite this proviso it appears that, while the plant breeding focus on later heading has markedly changed the timing of reproductive development, it has not changed the frequency or intensity of flowering in perennial ryegrass.

Less flowering intensity is desirable for animal performance as reproductive development results in higher stem: green leaf ratios and lower pasture NV (Waghorn et al. 2007). Further analysis of the present study (data not presented here) indicated that there was no difference between cultivars within the midseason group in flowering frequency or intensity at the final sampling event. However, the proportion of tillers that entered reproductive development at the final sampling varied between cultivars within the late- and very late-maturing groups, as some of these cultivars had a substantially lower proportion of reproductive tillers. It is not clear if these cultivars matured later than their nominal heading date suggested they should, or if they had a lower propensity to flower compared to other cultivars within the group. Further samplings events would have been required to address this question.

In conclusion, selection for later-heading perennial ryegrass cultivars has altered the temporal distribution of flowering; late- and very late-maturing cultivars do mature later and maintain a lower proportion of reproductive tillers during mid to late-spring when compared to mid-maturing material. There is little evidence to suggest that plant breeding has altered the intensity of flowering, however further information is required to quantify the flowering intensity of latematuring material.

\section{ACKNOWLEDGEMENTS}

The authors gratefully acknowledge the statistical expertise of B. Kuhn-Sherlock and the technical assistance of the DairyNZ technical staff. This work was funded by New Zealand dairy farmers through DairyNZ Inc.

\section{REFERENCES}

Bahmani, I.; Thom, E.R; Matthew, C.; Lemaire, G. 2002. Flowering propensity of two New Zealand perennial ryegrass cultivars originating from different ecotypes. New Zealand Journal of Agricultural Research 45: 129-137.

Cooper, J.; Calder, D. 1964. The inductive requirements for flowering of some temperate grasses. Grass and Forage Science 19: 6-14.

Fiorelli,C.; Woodward, S.; Wastney, M.; Thom, E.R.; Bahmani, I. 2001. Modelling factors affecting reproductive development of perennial ryegrass in Waikato dairy pastures. Proceeedings of the New Zealand Grassland Association 63: 165-170.

Forde, M.; Burgess, R.; Halligan, E.; Gardiner, S.; Latch, G. 1988. Varieties of Italian ryegrass in New Zealand. Proceedings of the New Zealand Grassland Association 49: 101-106.

Korte, C.J. 1986. Tillering in 'Grasslands Nui' perennial ryegrass swards 2 . Seasonal pattern of tillering and age of flowering tillers with two mowing frequencies. New Zealand Journal of Agricultural Research 29: 629-638.

Lee, J.M.; Matthew, C.; Thom, E.R.; Chapman, D.F. 2012. Perennial ryegrass breeding in New Zealand: a dairy industry perspective. Crop and Pasture Science 63: 107-127.

L'Huillier, P.J. 1987. Tiller appearance and death of Lolium perenne in mixed swards grazed by dairy cattle at two stocking rates. New Zealand Journal of Agricultural Research 30: 15-22.

Moore, K.J.; Moser, L.E.; Vogel, K.P.; Waller, S.S.; Johnson, B.E.; Pedersen, J.F. 1991. Describing and Quantifying Growth Stages of Perennial Forage Grasses. Agronomy Journal 83: 1073-1077.

Waghorn, G.C.; Burke, J.L.; Kolver, E.S. 2007. Principles of Feeding Value. pp. 35-60. In: Pasture and Supplements for Grazing Animals. Eds. Rattray, P.V.; Brookes, I.M.; Nicol, A.M. The New Zealand Society of Animal Production, Hamilton, New Zealand. 